\title{
Impervious Cover Variability in Urban Watersheds
}

\author{
Celina Bochis and Robert Pitt
}

An urban area inventory for watershed development conditions should be part of any comprehensive stormwater management plan, when the goal is to understand the sources of pollution and the magnitude of the expected runoff. The watershed inventory would, therefore, assist in the selection of the most beneficial stormwater control practices. The type of urban development in an area can have a major impact on the local hydrology and water environment. This inventory can therefore be used to support many decision making activities and to increase the success of local stormwater monitoring. Past studies (Schueler 1994; USEPA 1993; Arnold and Gibbons 1996; Booth and Jackson 1997) have demonstrated the importance of knowing the areas of the different land covers in each land use category and their storm drainage characteristics (grass swales, curb and gutters, and the roof drains). Increasing levels of impervious surfaces associated with urbanization result in higher volumes of runoff with higher peak discharges, shorter travel times, and more severe pollutant loadings. Urban imperviousness is an important indicator for urban watersheds in measuring the impact of land development on drainage systems and aquatic life (Schueler 1994). However, there are many different types of impervious surfaces, and their direct connectivity to the drainage system is an important attribute affecting stormwater runoff. The purpose of this chapter is to show the measured variability associated with land surface covers for different land uses in a large urban area in the state of Alabama.

Bochis, C. and R.E. Pitt. 2010. "Impervious Cover Variability in Urban Watersheds." Journal of Water Management Modeling R236-09. doi: 10.14796/JWMM.R236-09.

(C) CHI 2010 www.chijournal.org ISSN: 2292-6062 (Formerly in Dynamic Modeling of Urban Water Systems. ISBN: 978-0-9808853-3-0) 
There are a lot of assumptions about impervious area characteristics for different types of land uses, but very little data has been available to validate these assumptions. As part of this research, the Little Shades Creek watershed (Jefferson County, near Birmingham, Alabama) and five highly urbanized drainage areas situated in Jefferson County (in and near the city of Birmingham) were surveyed in detail to determine the actual development characteristics and their variability. Jefferson County is the largest county by population and fifth by size (NACo 2001) in the state of Alabama, having Birmingham as the county seat. This was historically a heavily industrialized area. Rainfall occurs year around, although it is generally driest in the fall. About 55 in. $(1400 \mathrm{~mm})$ rainfall occurs in a normal year, but recent years have been marked by a significant drought. With the decreased rainfall, more attention is being placed on regional water resources, including stormwater.

To determine how land development variability affects the quantity and quality of runoff, different land surfaces (roofs, streets, landscaped areas, parking lots, etc.) for different land uses (residential, commercial, industrial, institutional, etc.) were directly measured. Surface cover of 125 neighborhoods located in the Little Shades Creek watershed and 40 neighborhoods located in five of Jefferson County's highly urbanized drainage areas were analyzed to determine the actual development characteristics and their variabilities. The locally verified Source Loading and Management Model (WinSLAMM) (Pitt and Voorhees 1995; 2002) was then used to determine the sources of runoff, and to predict its volume. Statistical analyses were conducted at several levels to establish the quantitative and qualitative runoff sensitivity associated with variations of site characteristics.

\subsection{Methods for Impervious Area Estimation}

Imperviousness is an important indicator for analyzing and measuring the impact of urbanization on drainage systems and aquatic life because the impervious cover is a variable that can be quantified for different types of land development and has long been found to be directly related to the amount and rate of runoff from an area (Schueler 1994; Arnold and Gibbons 1996; Booth and Jackson 1997).

Urban imperviousness is site-specific and can be complicated to measure. There are several methods used to measure the actual and effective impervious cover, some of which are more accurate than others. These methods include direct measurement from aerial photographs and satellite imagery, estimation of impervious cover based on land use, estimation from road density (length of 
road per unit area), and estimation of impervious cover from population data. The most common methods of determining directly connected impervious cover are field measurements and empirical equations. Several studies have dealt with imperviousness and its estimation (as reported by Heaney et al. 1977; Boyd et al. 1993, 1994; Novotny and Olem 1994; Debo and Reese 2003). Table 9.1 shows some of the studies that have estimated or measured impervious cover for different regions.

Table 9.1 Percentages of impervious cover for various land uses having as source different studies.

\begin{tabular}{|c|c|c|c|c|c|c|}
\hline Land Use & $\begin{array}{c}\text { Density } \\
\text { (units/acre) }\end{array}$ & $\begin{array}{l}\text { Northern Virginia } \\
\text { (NVPDC 1980) }\end{array}$ & $\begin{array}{c}\text { TR-55 } \\
\text { NRCS (USDA } \\
1986) \\
\end{array}$ & $\begin{array}{c}\text { Puget Sound, WA } \\
\text { (Aqua Terra } \\
\text { 1994) }\end{array}$ & $\begin{array}{c}\text { Rouge River, MI } \\
\text { (Kluitenberg } \\
\text { 1994) }\end{array}$ & $\begin{array}{c}\text { Olympia, WA } \\
\text { (COPWD } \\
1995) \\
\end{array}$ \\
\hline Forest & & 1 & - & - & 2 & - \\
\hline Agriculture & - & 1 & - & - & 2 & - \\
\hline Open Land & - & - & - & - & 11 & - \\
\hline Low Density & $<0.5$ & $2-6$ & - & \multirow{3}{*}{10} & \multirow{3}{*}{19} & \multirow{3}{*}{-} \\
\hline Residential & 0.5 & 9 & 12 & & & \\
\hline & 1 & 12 & 20 & & & \\
\hline Medium & 2 & 18 & 25 & - & \multirow{3}{*}{19} & - \\
\hline Density & 3 & 20 & 30 & \multirow{2}{*}{$\begin{array}{l}- \\
40\end{array}$} & & \multirow{2}{*}{40} \\
\hline Residential & 4 & 25 & 38 & & & \\
\hline $\begin{array}{l}\text { High Density } \\
\text { Residential }\end{array}$ & $5-7$ & 35 & 65 & 40 & 38 & 40 \\
\hline Multifamily & Townhouse & 40 & \multirow{2}{*}{65} & \multirow{2}{*}{60} & \multirow{2}{*}{51} & \multirow{2}{*}{48} \\
\hline all $>7$ & Apartments & 50 & & & & \\
\hline units/acre & High Rise & $60-75$ & - & - & - & - \\
\hline Commercial & - & $90-95$ & 85 & 90 & 56 & 86 \\
\hline Institutional & - & - & - & - & - & - \\
\hline Industrial & - & $60-80$ & 72 & 90 & 76 & 86 \\
\hline Roadway & - & - & - & - & - & - \\
\hline
\end{tabular}

\begin{tabular}{|c|c|c|c|c|c|c|}
\hline Land Use & $\begin{array}{c}\text { Density } \\
\text { (units/acre) }\end{array}$ & $\begin{array}{l}\text { Holliston,MA } \\
\text { (CRWA 1999) }\end{array}$ & $\begin{array}{c}\text { Connecticut } \\
\text { (Prisloe 2000) }\end{array}$ & $\begin{array}{c}\text { Chesapeake Bay } \\
\text { (CWP 2000) }\end{array}$ & $\begin{array}{l}\text { Birmingham, AL } \\
\text { (Bochis 2007) }\end{array}$ & $\begin{array}{l}\text { Simple Method } \\
\text { (Schueler 1987) }\end{array}$ \\
\hline Forest & & 1 & - & - & & - \\
\hline Agriculture & - & 1 & - & 2 & & - \\
\hline Open Land & - & $7-23$ & - & 9 & 13 & - \\
\hline \multirow{3}{*}{$\begin{array}{l}\text { Low Density } \\
\text { Residential }\end{array}$} & $<0.5$ & 12 & $7-10$ & - & - & \multirow{3}{*}{10} \\
\hline & 0.5 & 9 & 12 & 11 & - & \\
\hline & 1 & 12 & 20 & 14 & 18 & \\
\hline Medium & 2 & 14 & $14-21$ & 21 & \multirow{3}{*}{22} & 30 \\
\hline Density & 3 & 20 & 30 & - & & \multirow{2}{*}{40} \\
\hline Residential & 4 & 25 & 38 & 28 & & \\
\hline $\begin{array}{l}\text { High Density } \\
\text { Residential }\end{array}$ & $5-7$ & 19 & 28 & 33 & 30 & 40 \\
\hline Multifamily & Townhouse & 47 & \multirow{2}{*}{39} & 41 & 35 & 60 \\
\hline all $>7$ & Apartments & 50 & & 44 & 42 & - \\
\hline units/acre & High Rise & - & - & - & - & - \\
\hline Commercial & - & 45 & 54 & 72 & 73 & 85 \\
\hline Institutional & - & - & - & 34 & 46 & - \\
\hline Industrial & - & 60 & 53 & 53 & 59 & 75 \\
\hline Roadway & - & - & - & - & 58 & 80 \\
\hline
\end{tabular}


Booth and Jackson (1997) explained the limitations of using total impervious area (TIA) in urban hydrology analyses and suggested using directly connected impervious area (DCIA) to describe urban development, but noted that its direct measurement is complicated. Consequently, empirical equations for determining DCIA have been developed as part of several different studies (Alley and Veenhuis 1983; Laenen 1983; Sutherland 2000). Alley and Veenhuis (1983) developed an empirical equation that shows the relationship between the directly connected impervious area and the total impervious area for a highly urbanized area in Denver, Colorado:

$$
D C I A=0.15 \times T I A^{1.41}
$$

where:

$$
\begin{aligned}
D C I A & =\text { directly connected impervious area }, \text { and } \\
T I A & =\text { total impervious area }
\end{aligned}
$$

Sutherland (2000) developed an equation based on U.S. Geological Survey (USGS) work completed in Portland and Salem, Oregon, that describes the relationship between effective impervious area (EIA or DCIA) and total impervious and has its general form as:

$$
E I A=A \cdot(T I A)^{B}
$$

where:

$$
\begin{aligned}
E I A= & \text { effective impervious area }(\%), \\
T I A= & \text { total impervious area, and } \\
& A, B \text { are such that if TIA }=1 \text { then EIA }=0 \\
& \text { if TIA }=100 \text { then EIA }=100
\end{aligned}
$$

Equation 9.2 has the same form as that used by Alley and Veenhuis (1983) This equation has several alternatives, known as the Sutherland equations (Sutherland 2000), developed to apply to various conditions of subbasins which might exist in a watershed.

Values of imperviousness can vary significantly according to the method used to estimate the impervious cover (Lee and Heaney 2003; Ackerman and Stein 2008). These researchers concluded that the main focus should be on DCIA when examining the effects of urbanization on stormwater quantity and quality.

Reducing the DCIA by disconnecting the impervious surfaces (sidewalks, rooftops, parking areas, and streets) from the drainage system will not restore hydrologic function to pre-development levels, but will improve the base flows, lessen the frequency of bank erosion, and improve stream functions. From a 
hydrological point of view, road-related imperviousness usually has larger im pact than rooftop-related imperviousness because roadways are usually directly connected while roofs can be hydrologically disconnected (Schueler 1994).

\subsection{Methodology}

\subsubsection{Geographical Location}

As part of this research, 165 neighborhoods which are part of Little Shades Creek watershed and five highly urbanized drainage areas situated in Jefferson County, Alabama (in and near the city of Birmingham), were surveyed in detail to determine their actual development characteristics and variability (Figure 9.1).

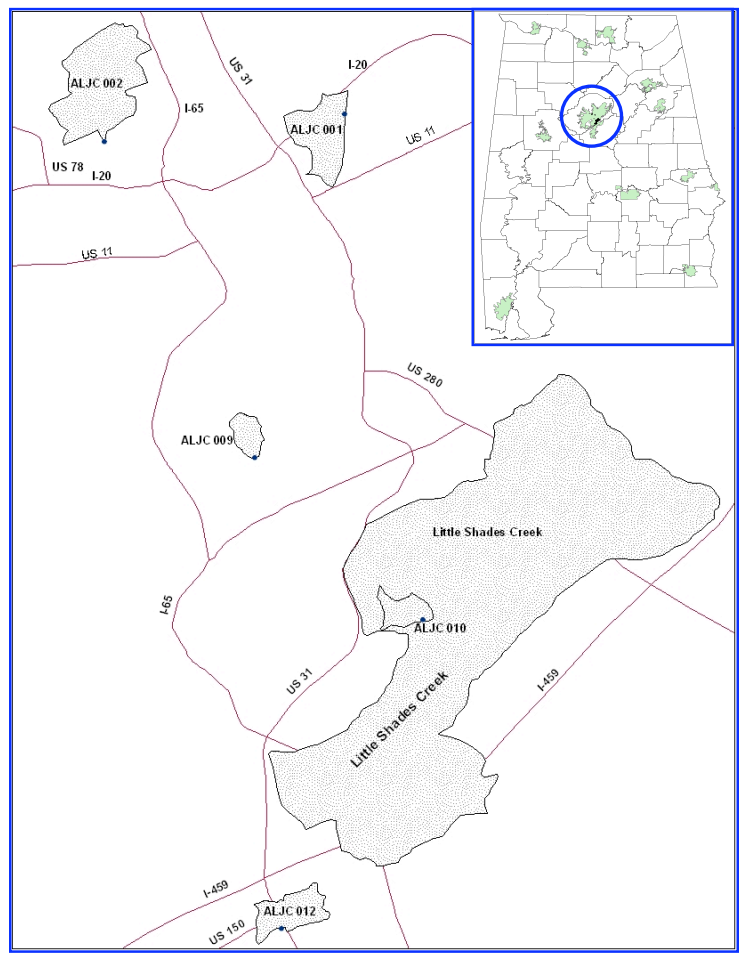

Figure 9.1 Location of Jefferson County, Alabama, and study watersheds. 
Birmingham is the largest city in Alabama and historically was a heavily industrialized (manufacture of coal, iron, and steel, textiles, chemicals, automotive parts) and urbanized area, but service businesses and education are now very important to the local economy.

According to the EPA rain zone map (USEPA 2004), Alabama belongs to EPA rain zone 3 (Southeast rain zone) which has about 110 rains $/ y>0.01$ in. $(0.25 \mathrm{~mm})$, with an average precipitation of $55 \mathrm{in} .(1400 \mathrm{~mm})$. The USDA Soil Conservation Service (SCS 1986) designated Birmingham, Alabama, to be in the type III rainfall distribution for TR-55 and TR-20 hydrology analyses.

\subsubsection{Description of Study Areas}

Many types of land development are represented in the six watersheds, even though the residential areas, mostly single family residential units, are predominant. Ten land use categories belonging to major land uses such as residential, commercial, institutional, industrial, and open space were surveyed by investigating $>10$ neighborhoods for each land use.

The residential land was subdivided according to the density type. Table 9.2 shows the study watersheds and their predominant land uses.

Table 9.2 Study watersheds and their predominant land use (percentage of total watershed area); the columns may not add to $100 \%$ due to rounding.

\begin{tabular}{lcccccc}
\hline \multicolumn{1}{c}{ Land Use } & $\begin{array}{c}\text { ALJC } \\
001\end{array}$ & $\begin{array}{c}\text { ALJC } \\
002\end{array}$ & $\begin{array}{c}\text { ALJC } \\
009\end{array}$ & $\begin{array}{c}\text { ALJC } \\
010\end{array}$ & $\begin{array}{c}\text { ALJC } \\
012\end{array}$ & $\begin{array}{c}\text { Little Shades } \\
\text { Creek }\end{array}$ \\
\hline $\begin{array}{l}\text { High Density } \\
\text { Residential }\end{array}$ & 0 & 3 & 89 & 0 & 0 & 4 \\
$\begin{array}{l}\text { Med. Density } \\
\text { Residential }\end{array}$ & 1 & 11 & 0 & 0 & 0 & 27 \\
Low Density & 8 & 0 & 0 & 83 & 0 & 9 \\
Residential & 0 & 0 & 0 & 0 & 25 & 13 \\
Apartments & 12 & 3 & 4 & 0 & 75 & 6 \\
Commercial & 0 & 1 & 7 & 0 & 0 & 9 \\
Institutional & 62 & 76 & 0 & 0 & 0 & 2 \\
Industrial & 6 & 7 & 0 & 18 & 0 & 24 \\
Open Space & 11 & 0 & 0 & 0 & 0 & 7 \\
Freeways & & & 0 & & & \\
\hline Area (Acre/ha) & $341(138)$ & $721(292)$ & $102(41)$ & $133(54)$ & $228(92)$ & $5120(2072)$ \\
\hline
\end{tabular}

All surveyed residential areas (high density, medium density, low density, apartments, and multi-family complexes) had pitched roofs that drained mainly to pervious surfaces with the only exception being multi-family areas. Some 
landscaping was present near the roads and was mostly lawns and evergreen shrubs. Streets and driveways had asphalt as the most common pavement material and had intermediate texture. The predominant drainage system was composed of concrete curbs and gutters in good or fair condition with a small percentage of grass swales in high and medium density residential areas.

Commercial land use was represented in the watersheds by office parks and shopping centers with flat roofs draining mostly to impervious areas. Lawns and evergreen shrubs in excellent condition were found near the roads. The paved parking lots represented the largest connected impervious source areas. The runoff from the roofs drains directly to parking areas and then to the drainage systems that were mostly curbs and gutters in good condition. The streets, driveways and parking areas were paved with asphalt having intermediate or smooth texture.

Schools and churches represented the institutional land use category of the drainage areas. The school roofs were flat and drained slightly more toward impervious surfaces than to pervious areas. However, school playgrounds were mostly unpaved. Churches had pitched roofs that drained to impervious areas. Landscape areas had an even distribution of deciduous and evergreen shrubs. Lawns were near the streets. Streets and parking lots were paved with asphalt and had intermediate textures. The drainage systems had both grass swales and curbs and gutters, all in fair condition.

The industrial land uses included a lumber manufacturing facility, several equipment storage and office complexes, a public mini-storage facility, a construction supply center, a door manufacturer, an automobile scrapyard, and a steel factory. The facilities were similar with all buildings being directly connected to the stormwater collection system. All facilities were closely bounded by other developments, roads, and steep banks. The industrial sites were medium to small size, covering no more than a few acres and they were all dominated by parking, storage areas, and roofs.

The open space land use included parks, cemeteries, a golf course, vacant land, and areas under construction. The few roofs that were found in the vacant land use and golf course areas drained to pervious areas. The parking lots were paved and directly connected to the drainage system. The stormwater drainage system was a combination of curbs and gutters and grass swales.

The drainage system in the freeway land use was comprised of grass swales in the medians and at the shoulders. The pavement was asphalt, with a smooth texture.

The soil of Little Shades Creek watershed and the five Jefferson County drainage areas is sandy loam and silt loam, in about equal amounts, but is highly disturbed due to the extensive land development. 


\subsubsection{Field Data Collection}

The gathering of the field data and the aerial photograph measurements for Little Shades Creek watershed were performed as part of an early study conducted by the University of Alabama at Birmingham, the Jefferson County office of the U.S. Natural Resources Conservation Service (NRCS), the U.S. Army Corps of Engineers, and other city and county governments. The field data collection effort for the five additional Jefferson County drainage basins reported in this chapter was performed during the lead author's master's thesis research (Bochis 2007).

For residential land uses, the most visible neighborhoods (having minimal tree cover) were selected and their individual elements were measured. However, for industrial, commercial, and institutional areas, it was necessary to take account of all the elements incorporated into the land use due to greater variabilities of the different surface cover areas. Normalization of the actual area measurements so they summed to $100 \%$ was used to account for minor rounding errors in data recording.

Every impervious surface was checked in the field to estimate its properties and connectivity. Streets were classified according to their drainage system: with curb and gutter (directly connected to the storm drainage system) or with swales (disconnected). Also, the pavement material of every street and parking lot was examined and classified.

\section{3 Results and Discussions}

\subsubsection{Impervious Cover Variability}

Regardless of the method used to estimate imperviousness, field verification is necessary because it is the only accurate method that can be used to estimate the directly connected portion of the impervious cover (Gregory et al. 2005). Aerial photographs and satellite images were used to assist in the measurement of the actual coverage of each type of surface in each neighborhood studied, and were used to supplement the field collection information.

It was found that there is considerable variability in total impervious cover for all watersheds. The box plots in Figure 9.2 show the total impervious cover variability within the study watersheds, also reflecting the differences in watersheds' surface covers. 


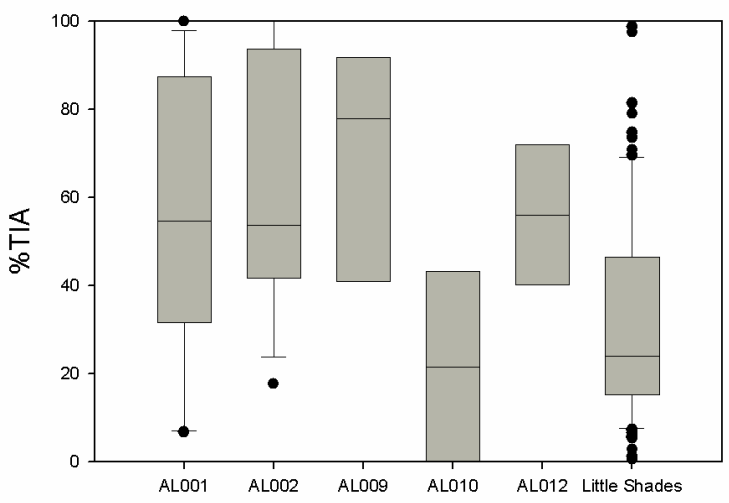

Figure 9.2 Total impervious area for study watersheds.

Table 9.3 shows the percentage impervious and pervious coverage for the land uses found in the Birmingham, Alabama, study areas. This table along with Table 9.4 and Figure 9.3 show that impervious areas in the six Jefferson County watersheds are almost entirely directly connected, and that there is a large variability among and within the land uses.

Table 9.3 Imperviousness percentage based on land uses in

Birmingham, Alabama (Bochis 2007).

\begin{tabular}{lccc}
\hline \multicolumn{1}{c}{ Land Use } & $\begin{array}{c}\text { Total Impervious } \\
\text { Area (\%) }\end{array}$ & $\begin{array}{c}\text { Directly Connected } \\
\text { Impervious Area (\%) }\end{array}$ & $\begin{array}{c}\text { Pervious } \\
\text { Area (\%) }\end{array}$ \\
\hline High Density Residential & 30 & 19 & 70 \\
Medium Density Residential & 22 & 13 & 78 \\
Low Density Residential & 18 & 9 & 83 \\
High Rise Res/Apartments & 42 & 17 & 58 \\
Multi Family & 35 & 27 & 65 \\
Commercial & 73 & 72 & 27 \\
Institutional & 46 & 41 & 54 \\
Industrial & 59 & 50 & 41 \\
Open Space & 13 & 9 & 87 \\
Freeways & 58 & 0 & 42 \\
\hline
\end{tabular}

Table 9.4 shows the land uses with their average DCIA and the corresponding coefficients of variation for the studied areas. These drainage basins have most of the impervious surfaces directly connected to the drainage system, except for the low density residential and open space land uses which have the lowest connectivity and the greatest coefficient of variation. The other extreme 
case is the commercial land use, which has almost all impervious cover connected and little variability.

Table 9.4 Directly connected impervious areas in Birmingham, Alabama, watersheds.

\begin{tabular}{lccc}
\hline \multicolumn{1}{c}{ Land Use } & Range (\%) & Average (\%) & COV \\
\hline High Density Residential & $4-34$ & 19 & 0.48 \\
Medium Density Residential & $0-34$ & 13 & 0.68 \\
Low Density Residential & $0.3-30$ & 9 & 1.03 \\
High Rise Res/Apartments & $0-45$ & 17 & 0.97 \\
Multi Family & $8-60$ & 27 & 0.53 \\
Commercial & $34-100$ & 72 & 0.29 \\
Institutional & $5-76$ & 41 & 0.61 \\
Industrial & $0-100$ & 50 & 0.66 \\
Open Space & $0-41$ & 9 & 1.21 \\
\hline
\end{tabular}

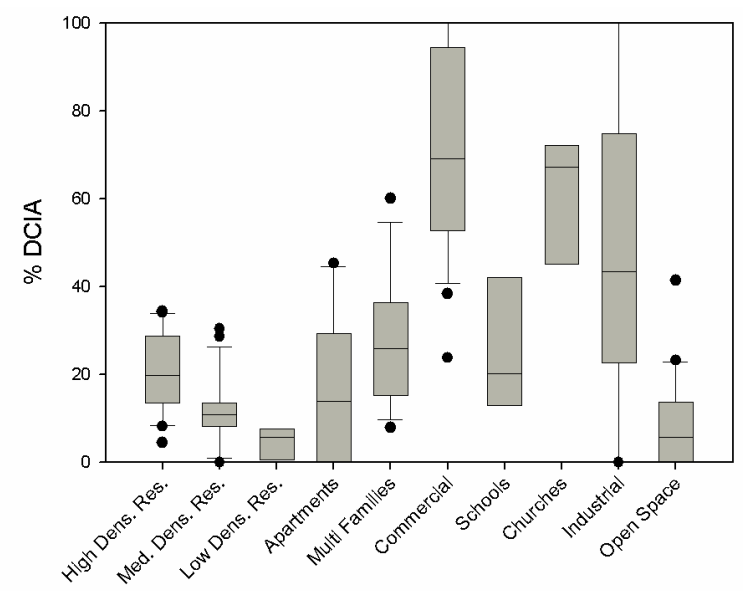

Figure 9.3 Percentage of directly connected impervious area by land use for Jefferson County, Alabama, watersheds (Bochis 2007)

Because of the high variability and scatter found in the data, as the box plots of DCIA show in Figure 9.3, it is more appropriate to subcategorize the DCIA by land uses, and fit the power and linear equations separately for each individual land use in the study areas. A power equation was fitted to the data based on the empirical equations for determining DCIA from TIA, as suggested in the literature. The overall plot shown in Figure 9.4 relates the directly connected impervious areas to the total impervious areas for all of the individual homoge- 
neous land use sites investigated. This plot shows that the combined study areas' DCIA might be a power function of TIA, as suggested by Sutherland (2000), and Alley and Veenhuis (1983). As noted above, these drainage basins have most of the impervious surfaces directly connected to the drainage system. The fitted equation for the entire study areas is comparable to one of the Sutherland equations used for highly connected areas where the drainage collector is a storm sewer with curb and gutters, and the roofs are connected.

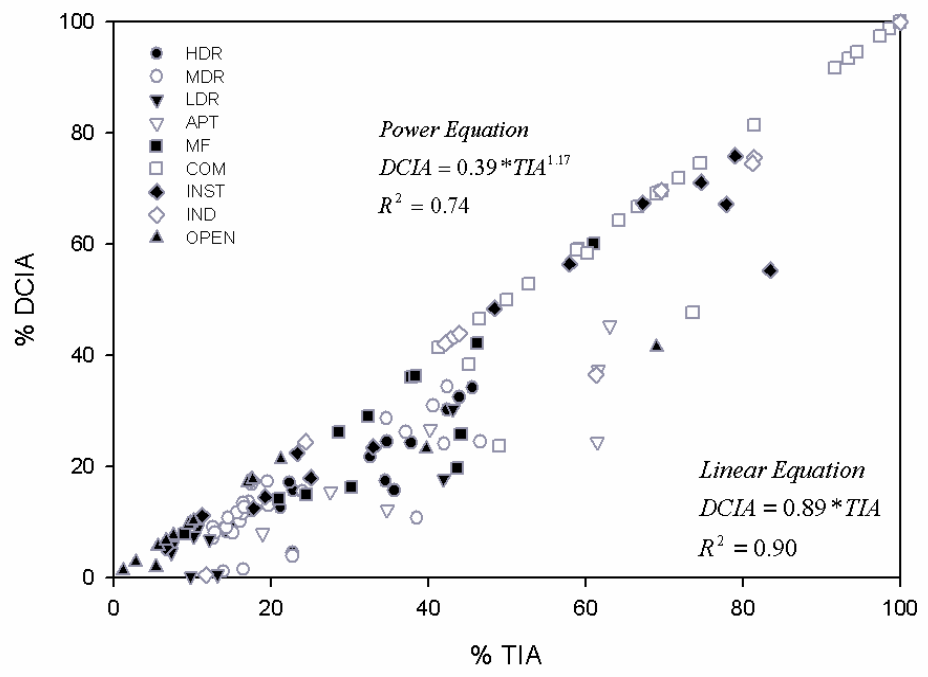

Figure 9.4 Empirical estimation of DCIA based on TIA for Birmingham, Alabama, study areas.

The power equation was fitted separately for each individual land use in the study areas. The A and B equation coefficients, along with their coefficients of determination are presented in Table 9.5. This data shows that the DCIA of each land use is not always a power function of TIA, suggesting that power fitting cannot always be successfully applied to the local conditions investigated. It was found that the linear equations better fit this local data (Table 9.5). Although not shown here, the fitted equations were all statistically significant using ANOVA (when the intercepts were not used) and that the residual behaviors were all acceptable.

Other reported literature impervious cover conditions are not very accurate when applied to local conditions (Table 9.1 above). These over- or underestimations will lead to significant changes in the modeled runoff volume. 
Table 9.5 Equation coefficients for each land use existent in Birmingham, Alabama, study area.

\begin{tabular}{lccccc}
\hline & \multicolumn{3}{c}{ Power Equation } & \multicolumn{2}{c}{ Linear Equation } \\
\hline \multicolumn{1}{c}{ Land Use } & A coeff. & B coeff. & $R^{2}$ value & A coeff. & $R^{2}$ value \\
\hline High Density Residential & 0.31 & 1.19 & 0.66 & 0.66 & 0.79 \\
Medium Density Residential & 0.42 & 1.09 & 0.36 & 0.61 & 0.62 \\
Low Density Residential & 0.22 & 1.16 & 0.27 & 0.54 & 0.77 \\
High Rise Res/Apartments & 0.22 & 1.22 & 0.83 & 0.55 & 0.66 \\
Multi Family & 0.74 & 1.00 & 0.77 & 0.80 & 0.72 \\
Commercial & 0.49 & 1.16 & 0.82 & 0.99 & 0.98 \\
Institutional & 0.75 & 1.04 & 0.97 & 0.88 & 0.92 \\
Industrial & 0.04 & 1.78 & 0.75 & 0.95 & 0.94 \\
Open Space & 1.05 & 0.92 & 0.91 & 0.67 & 0.87 \\
\hline
\end{tabular}

Figure 9.5 shows the average land cover distribution for medium density residential land use. For a typical medium density residential land use in this region having 2 units/acre to 6 units/acre ( 5 units/ha to 15 units/ha), the major land cover was found to be landscaped areas. About $22 \%$ of this land use area is covered by impervious surfaces broken down into three major subcategories: roofs, streets, and driveways.

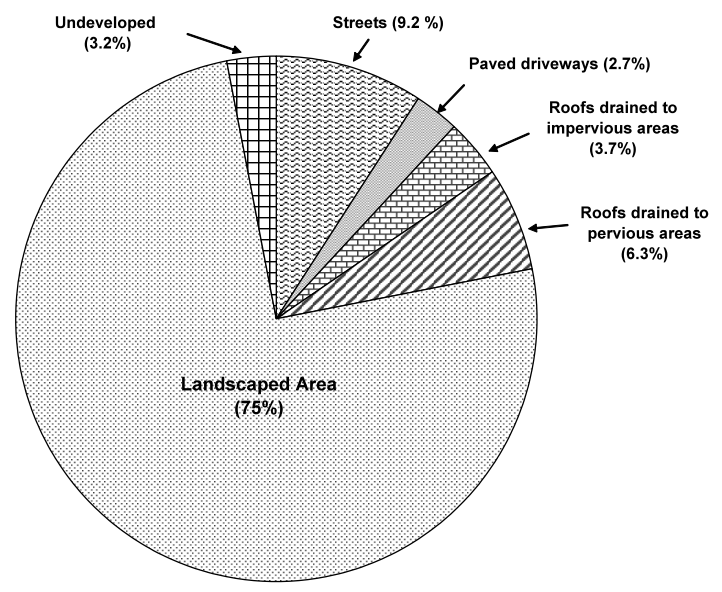

Figure 9.5 Medium density residential average land cover distribution (Bochis 2007).

Also, for a typical high density residential land use located in the Birmingham area, the total amount of impervious area for each category does not vary much (Figure 9.6). The pervious cover front and back yard components vary 
due to position of the house on the lot, but do not affect the total pervious cover variability. There is a similarity in the land cover distribution for all residential areas (high, medium and low density residential), but this trend is not obvious for other land uses such as commercial, industrial or institutional where the major land covers are parking lots, streets and connected roofs.

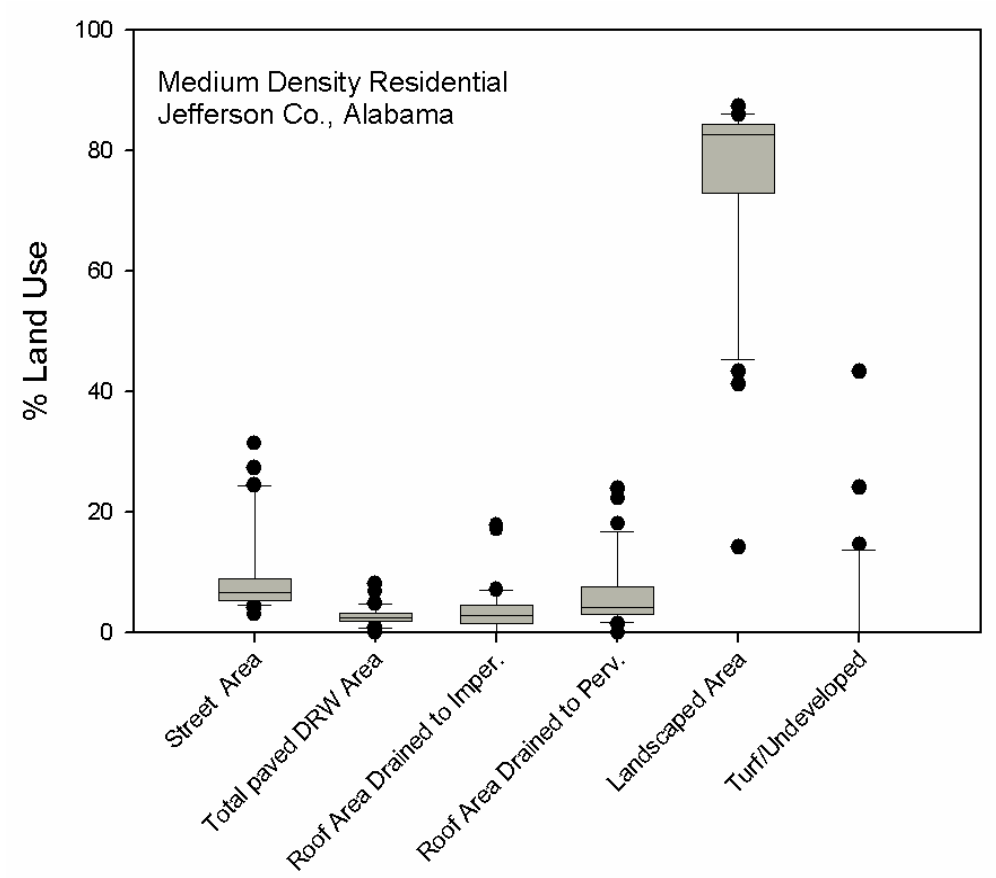

Figure 9.6 Medium density residential land cover distribution variations (Bochis 2007).

Table 9.6 Pearson's correlation matrix for field measurements; bold values are high correlations between pairs of parameters.

\begin{tabular}{lccccccccc}
\hline & DCIA & DSIA & Street & P'king & Dr'way & Con. roof & Dis. roof & L'scape & Perv \\
\hline DCIA & 1.000 & & & & & & & & \\
DSIA & -0.365 & 1.000 & & & & & & & \\
Street & 0.382 & 0.378 & 1.000 & & & & & & \\
P'king & $\mathbf{0 . 8 2 8}$ & -0.107 & 0.378 & 1.000 & & & & & \\
Dr'way & -0.096 & 0.073 & -0.137 & -0.231 & 1.000 & & & & \\
Con. roof & $\mathbf{0 . 7 1 1}$ & -0.226 & 0.143 & 0.495 & 0.058 & 1.000 & & & \\
Dis. roof & -0.147 & 0.300 & -0.124 & -0.191 & 0.148 & -0.237 & 1.000 & & \\
L'scape & $\mathbf{- 0 . 5 6 6}$ & 0.125 & -0.351 & $\mathbf{- 0 . 5 4 1}$ & 0.290 & -0.359 & 0.209 & 1.000 & \\
Perv. & -0.248 & -0.205 & -0.173 & -0.218 & -0.262 & -0.232 & -0.241 & $\mathbf{- 0 . 5 6 9}$ & 1.000 \\
Run. Vol. & $\mathbf{0 . 9 0 0}$ & -0.135 & $\mathbf{0 . 5 1 6}$ & $\mathbf{0 . 8 2 3}$ & -0.105 & $\mathbf{0 . 6 7 1}$ & -0.212 & $\mathbf{- 0 . 6 0 4}$ & -0.204 \\
\hline
\end{tabular}


Pearson correlation matrix was used to relate the magnitude of the relationships between field measurements for those six highly urbanized drainage areas in Jefferson County. Table 9.6 shows several high correlations between pairs of parameters $(>0.5)$. As an example, high correlations are seen between runoff volume and impervious surfaces, suggesting that runoff volume can be accurately predicted either by using streets, parking lot areas, and connected roofs or just by using DCIA. This fact is supported by the strong negative correlation among those components and pervious surfaces.

\subsubsection{Modeled Runoff Volumes}

The locally verified source loading and management model (WinSLAMM) (Pitt and Voorhees 1995; 2002) was used to investigate the relationship between watershed and runoff characteristics for each of the 165 neighborhoods.

The relationships between the directly connected impervious area percentages (DCIA \%) and the calculated volumetric runoff coefficients $\left(R_{v}\right)$ for each neighborhood was examined. The model was run using the actual land use characteristics for each site and $45 \mathrm{y}$ local rain data. The evaluation showed that there is a strong relationship between DCIA and $R_{v}$ parameters for both sandy and silty soil conditions existent in the watersheds (Figure 9.7).

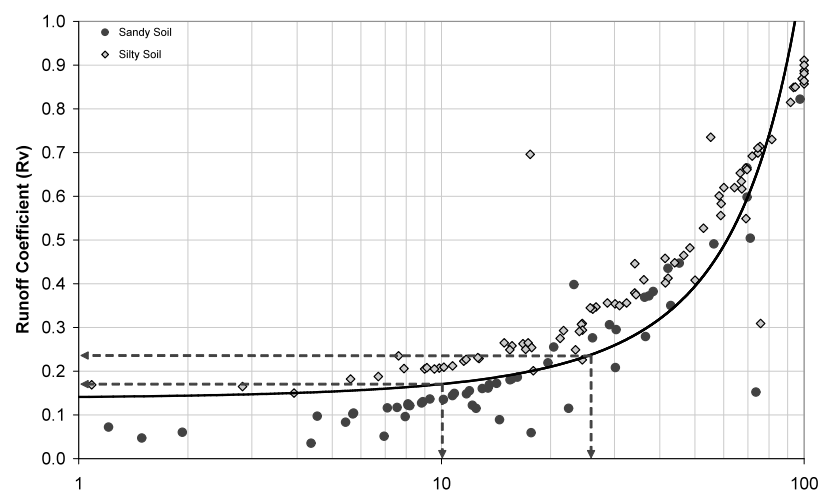

Figure 9.7 Relationships between the DCIA (\%) and the calculated volumetric runoff coefficients $R_{V}$ for each site surveyed by soil type.

The fitted exponential equations are:

Sandy soils (only): $R_{v}=0.097 e^{0.026 \times D C I A}\left(R^{2}=0.64\right)$

Silty soils (only): $R_{v}=0.192 e^{0.017 \times D C I A}\left(R^{2}=0.86\right)$ 


$$
\text { Overall: } \quad R_{v}=0.14 e^{0.021 \times D C I A}\left(R^{2}=0.71\right)
$$

where:

$$
\begin{aligned}
R_{v} & =\text { calculated volumetric runoff coefficient, } \\
R^{2} & =\text { coefficient of determination, and } \\
D C I A & =\text { directly connected impervious area }(\%) .
\end{aligned}
$$

It is important to note that $R_{v}$ is relatively constant until the $10 \%$ directly connected impervious cover values are reached (at $R_{v} \approx 0.17$ ), the point where receiving water degradation typically is observed to start. The $25 \%$ directly connected impervious level (where significant degradation is observed), is associated with $R_{v} \approx 0.23$ and is where the curve start to greatly increase in slope. When the modeled runoff coefficient is plotted for each land use, it is clearly shown (as expected) that the areas having the lowest impacts on water quality are the open space and medium density residential land uses, while the greatest impacts are associated with commercial, industrial and institutional land uses.

\subsubsection{Modeled Biological Condition in Receiving Stream Waters}

Table 9.7 is a summary of the existing land uses that were monitored as part of this research. The data shows that three watersheds are highly impervious, with

\begin{tabular}{|c|c|c|c|c|c|c|c|}
\hline $\begin{array}{l}\text { Drainage } \\
\text { Area ID }\end{array}$ & $\begin{array}{l}\text { Major Land } \\
\text { Use }\end{array}$ & $\begin{array}{c}\text { Area } \\
\text { (ha) }\end{array}$ & $\begin{array}{c}\text { Pervious } \\
\text { Areas } \\
(\%)\end{array}$ & $\begin{array}{c}\text { Directly } \\
\text { Connected } \\
\text { Impervious } \\
\text { Areas (\%) }\end{array}$ & $\begin{array}{l}\text { Disconnected } \\
\text { Impervious } \\
\text { Areas (\%) }\end{array}$ & $\begin{array}{l}\text { Volumetric } \\
\text { Runoff } \\
\text { Coefficient } \\
\text { (Rv) }\end{array}$ & $\begin{array}{c}\text { Receiving } \\
\text { Waters } \\
\text { Modeled } \\
\text { Biological } \\
\text { Conditions }\end{array}$ \\
\hline ALJC 001 & Industrial & 138 & 25 & 72 & 2.8 & 0.67 & Poor \\
\hline ALJC 002 & Industrial & 292 & 40 & 53 & 7.3 & 0.51 & Poor \\
\hline ALJC 009 & $\begin{array}{l}\text { H. Density } \\
\text { Residential }\end{array}$ & 41 & 54 & 34 & 12 & 0.37 & Poor \\
\hline ALJC 010 & $\begin{array}{l}\text { L. Density } \\
\text { Residential }\end{array}$ & 54 & 64 & 28 & 7.9 & 0.30 & Poor \\
\hline ALJC 012 & Commercial & 92 & 36 & 61 & 3.4 & 0.61 & Poor \\
\hline Little Shades & M. Density & 2072 & 67 & 21 & 12 & 0.29 & Poor \\
\hline Creek & Residential & & & & & & \\
\hline
\end{tabular}
$>50 \%$ of the watershed being composed of impervious cover.

Table 9.7 Runoff quantity and source area drainage connections by land use for Birmingham, Alabama, sites (Bochis 2007).

The expected biological conditions of the receiving waters, modeled based on actual field measurements using WinSLAMM, were calculated to be poor based on the Center for Watershed Protection's (1998) impervious cover model. In this analysis only the base conditions having no stormwater controls were considered. The fact that receiving waters are in poor biological condition was 
confirmed by in-stream investigations by biologists of the Storm Water Management Authority Inc. at Birmingham.

The highly impervious watersheds (ALJC001 and ALJC012), which have mainly industrial and commercial land uses respectively, have higher values of $R_{v}(\approx 0.6)$ but lower values of TSS concentrations, compared to the watersheds dominated by residential land uses (ALJC009, ALJC010, and Little Shades Creek). In this area, the main sediment sources are the landscaped areas, and not the parking or storage areas, or streets. The residential watersheds are closer to the threshold between fair and poor expected biological conditions $\left(R_{v} \approx\right.$ about 0.25 ) than the industrial and commercial watersheds, as expected.

\section{4 Conclusions}

The data collected for the Jefferson County watersheds show that this area in Birmingham has a wide range of impervious cover (TIA from $0.6 \%$ to $100 \%$ ) with almost all impervious surfaces directly connected. Average impervious cover of those watersheds is about $39 \%$, of which about $25 \%$ is directly connected to the drainage system and $14 \%$ drains to pervious areas (Table 9.3 above). It was also found that the variability of the directly connected portion of impervious cover is smaller within land uses compared with the variability between the land use categories.

In the study area there is a lot of variability in runoff volume (measured or simulated) which is closely related to variability in development characteristics. However, development characteristics are very different and are influenced by the geographical location, so geographical location is an important factor to consider when developing equations to predict DCIA or when using literature values to model the local runoff volume.

Table 9.7 also shows the discharge conditions for the study drainage areas and confirms that three urban areas are highly impervious, with $>60 \%$ of the watershed areas being composed of impervious covers. It also shows the expected conditions in the local receiving waters due to the measured amounts of impervious cover from these local land uses. Runoff modeling showed that stream quality in the receiving waters may be damaged to severely damaged, confirmed by in-stream investigations. As expected, the area land use with the least impervious cover is open space (parks, cemeteries, golf course), and the land uses with the largest impervious covers are commercial areas, followed by industrial areas. It was found that for a typical residential land use located in the Birmingham area, the total amount of impervious area varies little. There is some variability between front and back landscaped areas, because of the posi- 
tion of the house on the lot, but the total amount of landscaped areas varies little for residential land use areas.

Urbanization radically transforms natural watershed conditions and introduces impervious surfaces into the previously natural landscape. Total impervious areas are mostly composed of rooftop and transportation related components that can be directly connected to or disconnected from the drainage system. The impervious areas that are directly connected to the storm drainage system are the greatest contributor of runoff and stormwater pollutant mass discharges under most conditions. The amount of impervious cover has become recognized as a tool for evaluating the health of a watershed and serves as an indicator of urban stream quality. Knowledge about the impervious surfaces, and how they can be managed, is an effective stormwater management tool and can be used to help reduce the impacts of developments within watersheds.

\section{Acknowledgments}

The authors would like to thank Stormwater Management Authority Inc. at Birmingham, Alabama, for their help with the monitoring data and satellite images, and the Jefferson County Earth Team of the local USDA office, who, in a volunteer effort, collected the Little Shades Creek field information during the mid-1990s.

\section{References}

Ackerman, Drew, and Eric Stein. 2008. Estimating the Variability and Confidence of Land Use and Imperviousness Relationships at a Regional Scale. Journal of the American Water Resources Association 44 (4): 996-1008.

Alley, William M., and Jack E. Veenhuis.1983. Effective Impervious Area in Urban Runoff Modeling. Journal of Hydraulic Engineering, 109 (2): 313-319.

Arnold, Chester, and James Gibbons. 1996. Impervious Surface Coverage. The Emergence of a Key Environmental Indicator. Journal of the American Planning Association 62 (2): 243-258.

Bochis, Celina. 2007. The Magnitude of Impervious Surfaces in Urban Areas. Master's Thesis. The University of Alabama at Tuscaloosa.

Booth, Derek, and Rhett Jackson. 1997. Urbanization of Aquatic Systems-Degradation Thresholds, Stormwater Detention, and the Limits of Mitigation. Journal of the American Water Resources Association 33 (5): 1077-1090.

Boyd M.J., M.C. Buffil, and R.M. Knee. 1993. Pervious and Impervious Runoff in Urban Catchments. Hydrological Sciences 38: 463-478.

Boyd M.J., M.C. Buffil, and R.M. Knee.1994. Predicting Pervious and Impervious Storm Runoff from Urban Drainage Basins. Hydrological Sciences 39: 321-332. 
Cappiella, Karen, and Ken Brown. 2001. Land Use and Impervious Cover in the Chesapeake Bay Region. Watershed Protection Techniques 3(4): 835-840.

Center for Watershed Protection. 1998. The Rapid Watershed Planning Handbook. Chapter 1. Ellicott City, MD.

Debo, Thomas, and Andrew Reese. 2003. Municipal Stormwater Management. Lewis Publishers, CRC Press, Boca Raton, FL.

Gregory, M., J. Aldrich, A. Holtshouse Brennan and K. Dreyfuss-Wells. 2005.

"Evaluation of Imperviousness Impacts in Large, Developing Watersheds." Journal of Water Management Modeling R225-06. doi: 10.14796/JWMM.R225-06.

Heaney, J. P., Huber, W. C., and Nix, S. 1977. Storm Water Management Model: Level I-Preliminary Screening Procedures. U.S. Environmental Protection Agency Rep. EPA-600/2-76-275, Washington, D.C.

Laenen, Antonius. 1983. Storm Runoff as Related to Urbanization Based on Data Collected in Salem and Portland and Generalized for the Willamette Valley, Oregon.

USGS Water Resources Investigations Report 83-4143: 88

Lee, Joong, and James Heaney. 2003. Estimation of Urban Imperviousness and its Impacts on Storm Water Systems. Journal of Water Resources Planning and Management 129(5): 419-426.

NACo (National Association of Counties). 2001. Website URL: http://www.naco.org/Template.cfm?Section=Find_a_County\&Template=/cffiles/cou nties /state.cfm\&statecode $=$ al (Accessed March 2009).

Novotny, Vladimir, and H. Olem. 1994. Water Quality: Prevention, Identification, and Management of Diffuse Pollution. Van Nostrand Reinhold, New York.

Pitt, Robert, and John Voorhees. 1995. Source Loading and Management Model (SLAMM). National Conference on Urban Runoff Management: Enhancing Urban Watershed Management at the Local, County, and State Levels. March 30 -April 2, 1993. USEPA. Center for Environmental Research Information. Cincinnati, OH: 225-243.

Pitt, Robert, and John Voorhees. 2002. SLAMM, the Source Loading and Management Model. In: Wet-Weather Flow in the Urban Watershed: Technology and Management (R. Field and D. Sullivan, Eds.). CRC Press, Boca Raton, FL: 103-139.

Schueler, Thomas. 1994. The Importance of Imperviousness: Watershed Protection Techniques. Center for Watershed Protection 1(3): 100-111.

SCS (U.S. Soil Conservation Service, now Natural Resources Conservation Service). 1986. Urban Hydrology for Small Watersheds. U.S. Department of Agriculture Technical Release No. 55.

Sutherland, Roger. 2000. Methods for Estimating the Effective Impervious Area of Urban Watersheds. In: The Practice of Watershed Protection (Edited by T. R. Schueler and H. K. Holland). Center for Watershed Protection, Ellicott City, MD: 193-195.

USEPA. 1983. Results of the Nationwide Urban Runoff Program. EPA 832-R-83-112 and PB 84-185552. Water Planning Division. Washington, D.C.

USEPA. 2004. National Pollutant Discharge Elimination System Compliance Inspection Manual (Appendix U). EPA 305-X-04-001. Office of Enforcement and Compliance Assurance. Washington, D.C. 